Research Article

\title{
THE PROPERTIES OF CADMIUM OXIDE-CARBON NANOTUBE NANOCOMPOSITE SYNTHESIZED VIA SOL-GEL METHOD
}

\author{
Öyküm BAŞGÖZ ${ }^{1}$, Ömer GÜLER ${ }^{2 *}$, M. Gökhan ALBAYRAK ${ }^{3}$, Mehmet TAKGÜN ${ }^{4}$ \\ In this study, cadmium oxide based carbon nanotube reinforced material was \\ produced and the optical and electrical properties of the obtained composite \\ were investigated. After the carbon nanotubes used as reinforcement material \\ were synthesized using the chemical vapor deposition method, they were \\ supplemented at different ratios to the commercially available cadmium oxide \\ powders. As another group of samples; cadmium oxide powders were \\ synthesized by the sol-gel method and the carbon nanotubes were again \\ supplemented at different ratios. Synthesized carbon nanotubes were \\ subjected to Transmission Electron Microscope examination. Composite \\ materials obtained were examined by Scanning Electron Microscope. Then, \\ the changes in the electrical conductivity of the composites obtained by \\ temperature were measured. The optical properties of the composites were \\ determined by taking $U V$-vis spectrometers.
}

Key words: Carbon Nanotube, Cadmium Oxide, Sol-Gel, Nanocomposite.

\section{Introduction}

In recent years, the application areas of metal oxides have grown to a large extent due to their new electrical, catalytic and optical properties, so researchers primarily work with these materials because of their optical and structural properties of metal oxides [1-4]. Transparent oxide conductors such as copper oxide $(\mathrm{CuO})$, zinc oxide $(\mathrm{ZnO})$, tin oxide $(\mathrm{SnO})$ and cadmium oxide $(\mathrm{CdO})$ are of interest due to their semiconductor optoelectronic properties (transparent in the visible region and electrically conducting) [5]. $\mathrm{CdO}$ is an n-type semiconductor. It has $2.2-2.8 \mathrm{eV}$ direct and $0.55 \mathrm{eV}$ indirect band gap and is used in many applications such as photodiode, solar cells in the result of low electrical resistance, high optical transparency [6-8]. CdO is n-type semiconductors in the rock salt crystal structure of $\mathrm{NaCl}$ (surface-centered cubic structure) [9]. Since CdO-structured semiconductors have an extraordinarily large carrier mobility in the visible region and good optical transparency, their use is increasing [10-12].

\footnotetext{
${ }^{1}$ Mersin University, Engineering Faculty, Metallurgical and Materials Eng. Dept., 33100, Mersin, Turkey oykumbasgoz@mersin.edu.tr

2 Mersin University, Engineering Faculty, Metallurgical and Materials Eng. Dept., 33100, Mersin, Turkey, oguler@mersin.edu.tr, http://orcid.org/0000-0003-0190-9630

${ }^{3}$ Firat University, Engineering Faculty, Metallurgical and Materials Eng. Dept., 23000, Elazig, Turkey mgalbayrak@firat.edu.tr

${ }^{4}$ Firat University, Engineering Faculty, Metallurgical and Materials Eng. Dept., 23000, Elazig, Turkey mehmet_takgun @hotmail.com

* Corresponding author; oguler@mersin.edu.tr,
} 
$\mathrm{CdO}$ is used in making photodiodes, solar cells, flat panel displays, optical communication, thin film resistors, phototransistors, photovoltaic, transparent conductive electrodes, liquid crystal displays and IR detectors due to their high conductivity, high permeability and low band gap properties [13-15]. The physico - chemical properties of $\mathrm{CdO}$ depend not only on chemical composition but also on size, shape, surface morphology and production technique [16]. There are many different methods for producing $\mathrm{CdO}$ in the literature. As a result of these methods, $\mathrm{CdO}$ acquisition at nano size is made possible. Physical, chemical and thermal hydrothermal methods [17-18], template assisted method [19], solvothermal method [20], mechanochemical method [21-22], thermal disruption method [23], photosynthetic method [24] sonochemical method [25] are production methods. Sol-gel technique for preparing pure and doped $\mathrm{CdO}$ films is a cost-effective method of controlling size and morphology [26], and nanoparticles are one of the most promising methods for synthesizing nanoparticles.

The idea of doping carbon nanotubes has attracted the attention of researchers because it allows them to control their electronic properties (intercalation reaction with electron donors or recipients) [27]. In addition, the absence of certain band voids in MWCNT provides added value to photovoltaic efficiency by absorbing light over a broad wavelength range [28]. Isolated CNTs have an electrical conductivity of $2 \times 10^{7} \mathrm{~s} / \mathrm{m}$, a capacitance of $10^{13} \mathrm{~A} / \mathrm{m}^{2}$ and a thermal conductivity of $3500 \mathrm{~W} / \mathrm{mK}$ [29].

The purpose of this work is to reinforce the above mentioned CNTs with very good electrical properties by using two different cadmium oxide matrices and to examine the change in electrical and optical properties that will occur in the structure compared to pure $\mathrm{CdO}$.

\section{Material and Method}

In this study, CdO synthesized by sol-gel method was used as matrix. CNTs synthesized by Chemical Vapor Deposition (CVD) method were used as reinforcement material and nanocomposites with $\mathrm{CdO}$ matrix were synthesized by powder metallurgy method. Carbon nanotube synthesis was performed using a single crystal silicon (100) substrate. This substrate was first washed with acetone followed by ethanol in an ultrasonic bath. Then, the substrate was placed in the middle of a tube furnace on a boat, the inside of the tube furnace was vacuumed with a pump and purged. The furnace was then heated to $650^{\circ} \mathrm{C}$ in an argon (Ar) atmosphere at a flow rate of 1 liter per minute through the system. After the tube furnace reached $650^{\circ} \mathrm{C}$, the flow of Ar gas was interrupted and acetylene $\left(\mathrm{C}_{2} \mathrm{H}_{2}\right)$ gas was introduced for 40 minutes. At the end of 40 minutes, the acetylene gas was cut off and the Ar gas was again supplied to the system until the furnace cooled to room temperature. Characterization of the obtained nanotubes was performed by X-ray diffraction (XRD) and transmission electron microscopy (TEM). Jeol Jem $2100 \mathrm{~F}$ brand TEM device was used.

Carbon nanotubes were added to the $\mathrm{CdO}$ synthesized by the sol-gel method at $0.1,0.2,0.5$ and $1 \%$ by weight. For a homogenous mixture, the alcohol carbon nanotube mixture was mixed in an ultrasonic mixer and then the appropriate amount of $\mathrm{CdO}$ was added. The alcohol was mixed with a magnetic stirrer until evaporation. The resulting powder mixture was pelletized by pressing at a pressure of $600 \mathrm{MPa}$ and then sintered at $450{ }^{\circ} \mathrm{C}$. In order to compare the properties of the sol-gel produced $\mathrm{CdO}$, the Acros Organic brand (Code: 223792500, 99\% purity) CdO was readily available. The production of the $\mathrm{H}_{1}$-encoded nanocomposite with the ready $\mathrm{CdO}$ matrix was similarly performed and compared with the CdO-matrix nanocomposite synthesized by the sol-gel method. 
Table 1. Codes and other characteristics of samples.

\begin{tabular}{ccc}
\hline Samples Codes & The type of CdO & $\begin{array}{c}\text { The amount of CNT } \\
(\% \mathbf{w})\end{array}$ \\
\hline $\mathrm{H}_{1}$ & Commercial & - \\
$\mathrm{S}_{1}$ & Sol-Gel & - \\
$\mathrm{S}_{2}$ & Sol-Gel & 0.1 \\
$\mathrm{~S}_{3}$ & Sol-Gel & 0.2 \\
$\mathrm{~S}_{4}$ & Sol-Gel & 1 \\
\hline
\end{tabular}

\subsection{Production of Carbon Nanotubes}

Fig. 1 shows the XRD analysis of carbon nanotubes produced by the chemical vapor deposition method. As can be seen, the powders gave both a violent and broad peak at about $26^{\circ}$, which overlaps with the peaks of the carbon nanotubes in the database of the XRD (Pixel analysis Diffrac Evaluation Software ICDD tag No. 00-058-1638). The fact that the pikes are wide indicates that the powders are nano-sized according to Debye-Scherrer equality. Debye-Scherrer equality;

$$
\mathrm{D}=0.9 \lambda / \beta_{\mathrm{hkl}} \cos \theta
$$

$\mathrm{D}$ is the crystal size, $\mathrm{B}$ is the maximum peak intensity half-peak width in radians, $\theta$ is the Bragg angle, $\lambda$ is the wavelength of the light used in the diffraction [29].

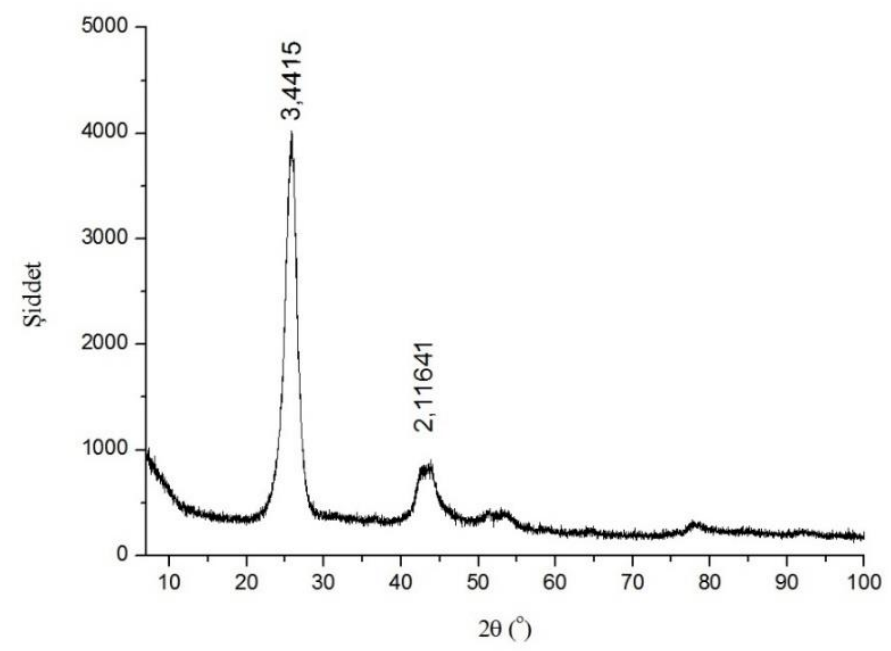

Figure 1. XRD analysis results of carbon nanotubes produced.
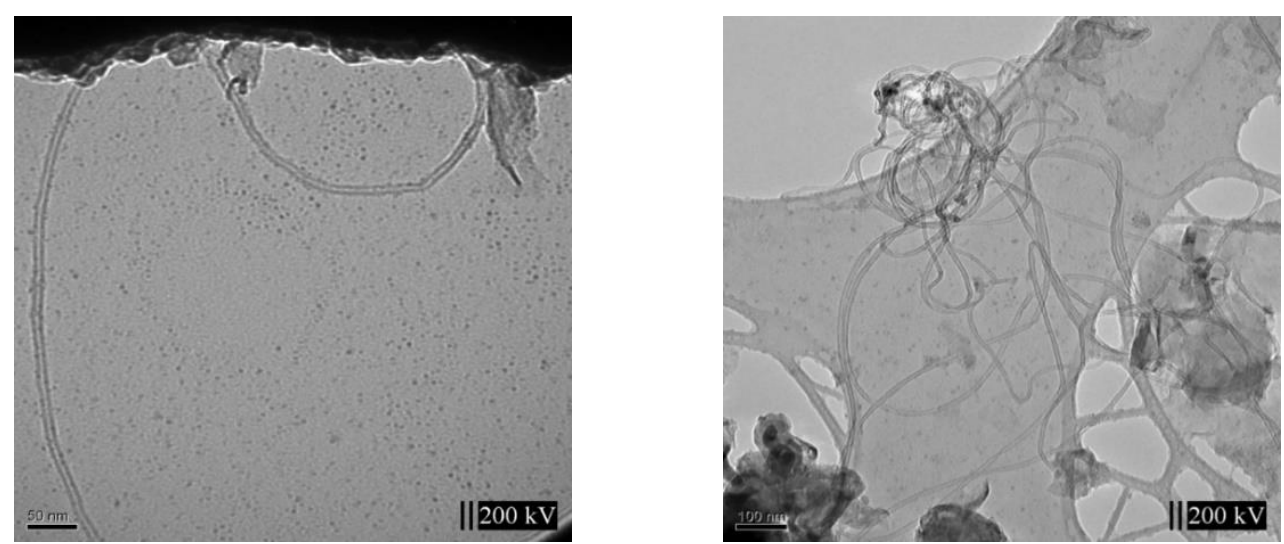

Fig. 2. TEM Images of the produced carbon nanotubes. 
TEM images of the carbon nanotubes produced in Fig. 2 are given. As can be seen, the structures obtained are carbon nanotubes. There is a gap in the middle of the structures obtained, and on both sides there are walls with certain thicknesses. The produced carbon nanotubes vary in diameter from 15 to $20 \mathrm{~nm}$ and vary in size from 1-5 $\mu \mathrm{m}$.

Some particles have black particles in the joint or tip (Fig. 2.b). These particles are nano-sized iron particles that have been used as catalysts during the synthesis of carbon nanotubes. Carbon nanotubes grow on these particles.

\subsection{Production of $\mathrm{CdO}$ with Sol-Gel}

For synthesis, 1 mole of cadmium acetate dihydrate was used, 46 moles of methanol, 0.2 moles of glycerol and 0.5 moles of triethylamine. Firstly, cadmium acetate was dissolved in 23 moles of methanol using a magnetic stirrer. Stirring is carried out until the mixture has a transparent color. Glycerol was added and then triethylamine and the remaining methanol mixture added. The whole mixture was stirred at $60{ }^{\circ} \mathrm{C}$ for 2 hours in a magnetic stirrer. The mixture was stirred at room temperature for 12 hours in a magnetic stirrer to obtain a homogeneous mixture. Calcination heat treatment was applied in order to remove the solvent in the thoroughly homogenized solutions by mixing. The resulting powder mixture was calcined at $600^{\circ} \mathrm{C}$ for 1 hour and a brown powder was obtained at the end of the treatment. The flow chart of the method mentioned in Fig. 3 is given.

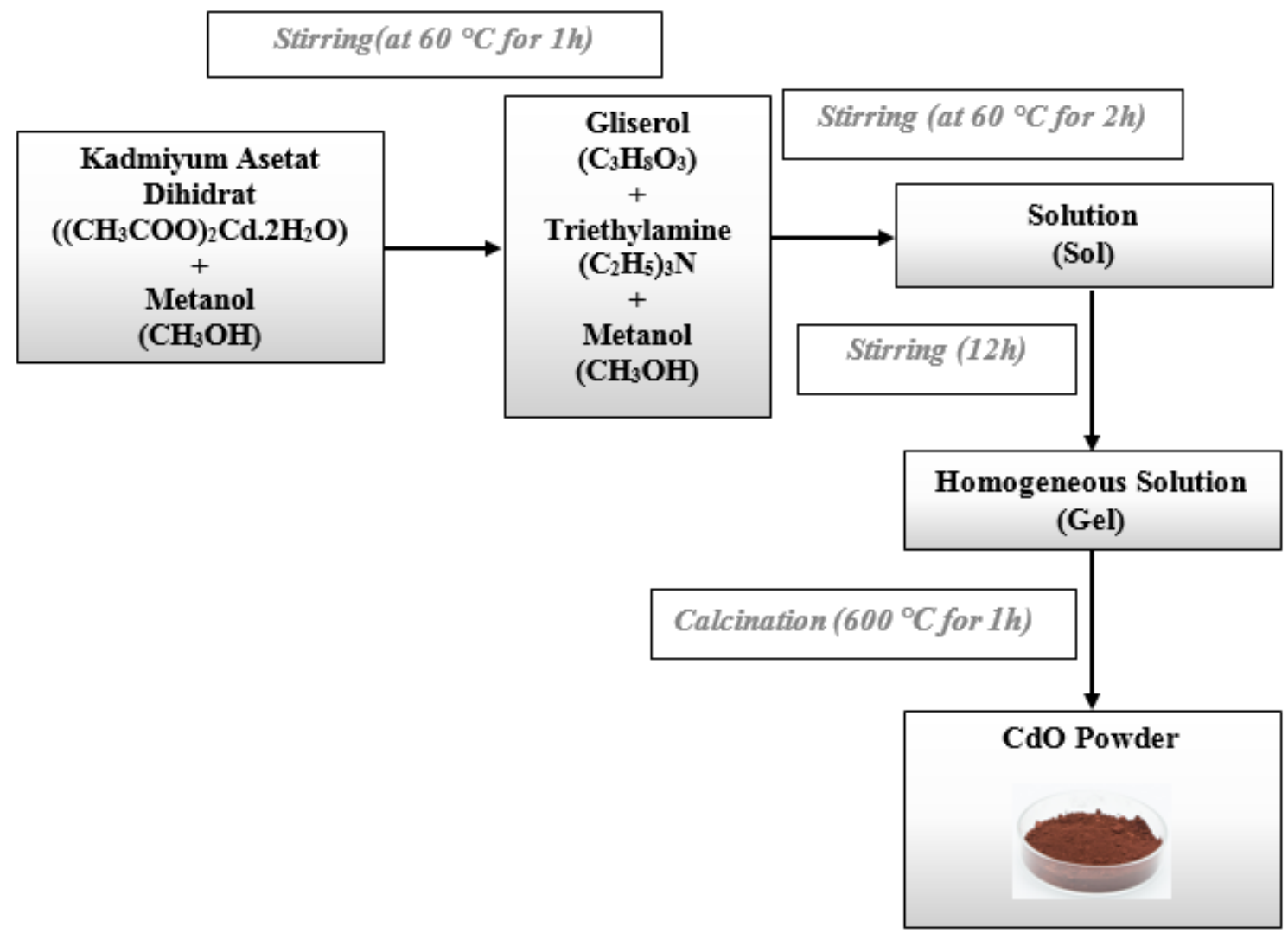

Figure 3. CdO synthesis flow diagram by sol-gel method. 


\section{Result and Discussion}

\subsection{Microstructure Examination Results of CdO-KNT Composite}

Microstructures of the resulting composites were determined by scanning electron microscopy. Jeol Jsm $7001 \mathrm{~F}$ electron microscope used in this study was used. In Figure 3, microstructure images of $H_{1}$ sample and $S_{x}$ series are given.
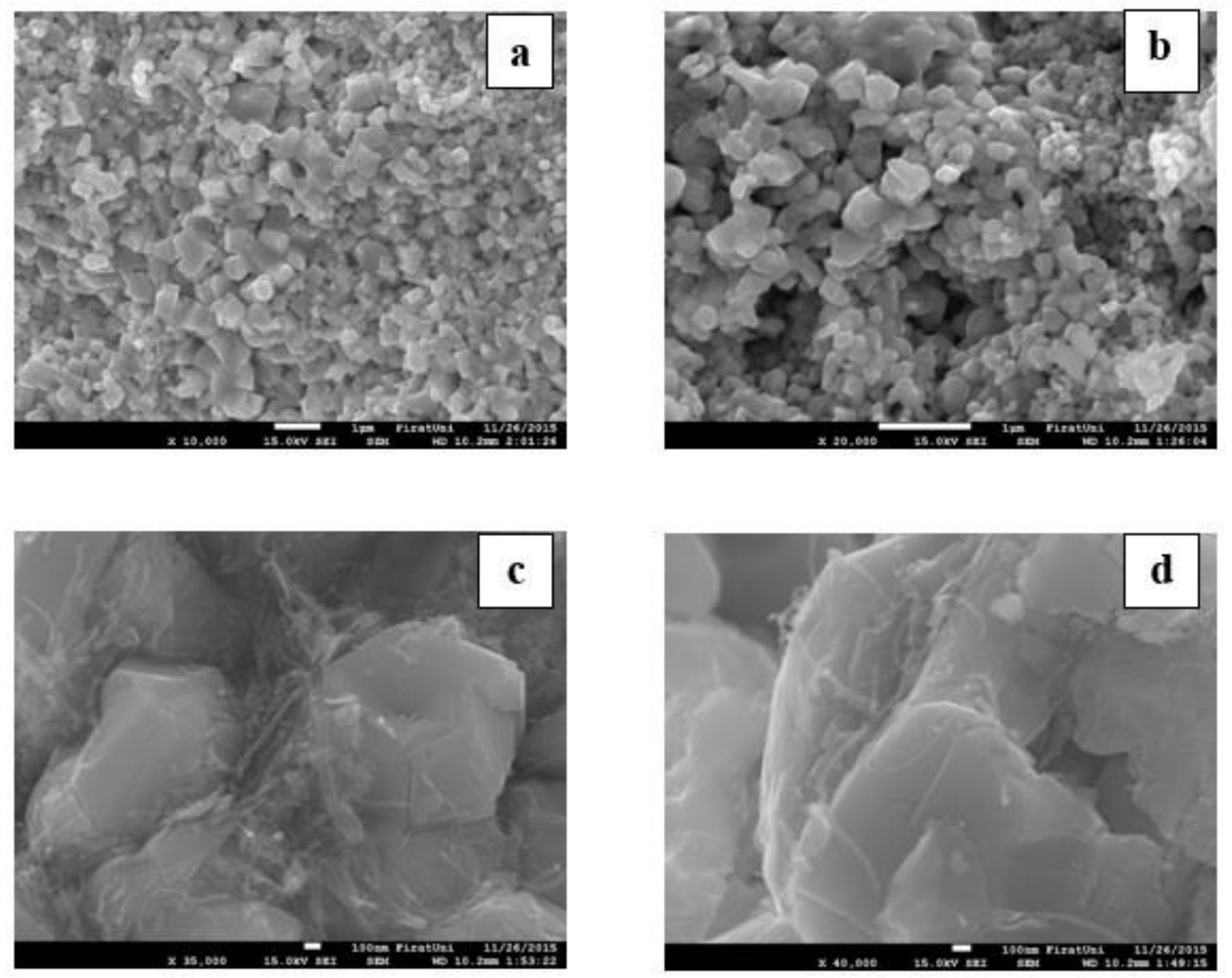

Figure 4. Microstructure images of $H_{1}$ sample and $S_{x}$ series. a) $H_{1}$, b) $S_{1}$, c) $S_{2}$, d) $S_{4}$ samples.

Figure 4.a gives a SEM image of sample $\mathrm{H}_{1}$. The $\mathrm{H}_{1}$ sample is commercially available pure $\mathrm{CdO}$. When the microstructure images are examined, a structure consisting of many particles in homogeneous and close to each other is seen.

In Figure 4.b, SEM image of $\mathrm{S}_{1}$ sample is given. Sample $\mathrm{S}_{1}$ is pure $\mathrm{CdO}$ produced by the sol-gel method. The structures formed as shown are homogeneous spherical shaped particles, the size of the particles being around $100 \mathrm{~nm}$.

Figure 4.c shows a SEM image of sample $S_{2}$. The sample $S_{2}$ is a CdO matrix $0.1 \% \mathrm{CNT}$ reinforced composite sample produced by the sol-gel method. It can be said that the CNTs are distributed homogeneously within the structure. In addition, there were not CNT pellets found in the structure.

In Figure 4.d, a SEM image of sample $\mathrm{S}_{4}$ is given. $\mathrm{S}_{4}$ sample is a composite sample of $\mathrm{CdO}$ matrise $1 \%$ CNT reinforced by the sol-gel method. Although there are homogeneously distributed regions of CNTs in the structure, it is not uncommon to find the regions where the CNTs are scattered and clustered as in the $\mathrm{H}_{5}$ sample. 


\subsection{Investigation of Electrical Properties of CdO-KNT Composite Samples Produced}

The conductivity of the produced semiconducting samples was changed according to the temperature by applying the temperature values in the range of 300-433 $\mathrm{K}$ by applying $0,5-5 \mathrm{~V}$ current in a dark environment. KEITHLEY 6517A electrometer was used to measure the current values of the samples according to the temperature. Figure 4 shows the electrical conductivity measurements of samples $S_{1}, S_{2}, S_{3}$ and $S_{4}$ respectively.

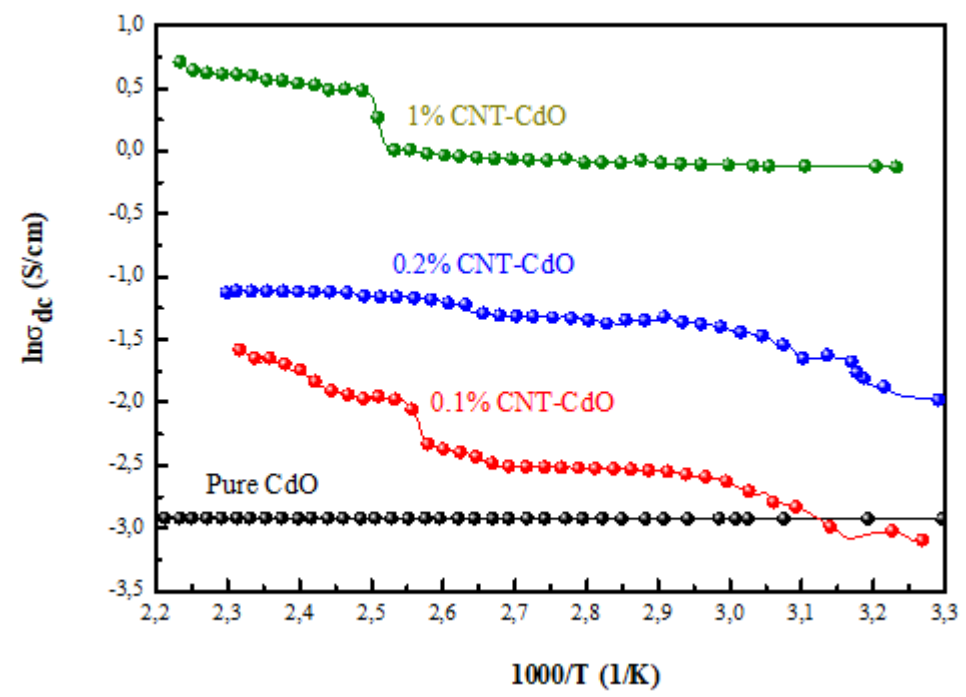

Figure 5. Electrical properties of composites of $S_{x}$ samples.

Conductivity values of pure $\mathrm{CdO}, 0.1 \%, 0.2$ and $1 \mathrm{CNT}$ doped CNT-CdO composites at room temperature were found to be $5.37 \times 10^{-2}, 4.9 \times 10^{-2}, 1.44 \times 10^{-1}$ and $8.8 \times 10^{-1} \mathrm{~S} / \mathrm{cm}$, respectively. These values show that the conductivity at room temperature of the composite increases with increasing KNT ratio compared to pure $\mathrm{CdO}$.

\subsection{Investigation of Optical Properties of CdO-CNT Composite Samples Produced}

In Fig. 6, reflection-wavelength spectrum graphs of $\mathrm{CdO}$ and $S_{1}, S_{2}, S_{3}$ and $S_{4}$ samples with 0.1, 0.2 and 1 CNT added by sol-gel method are given. ,

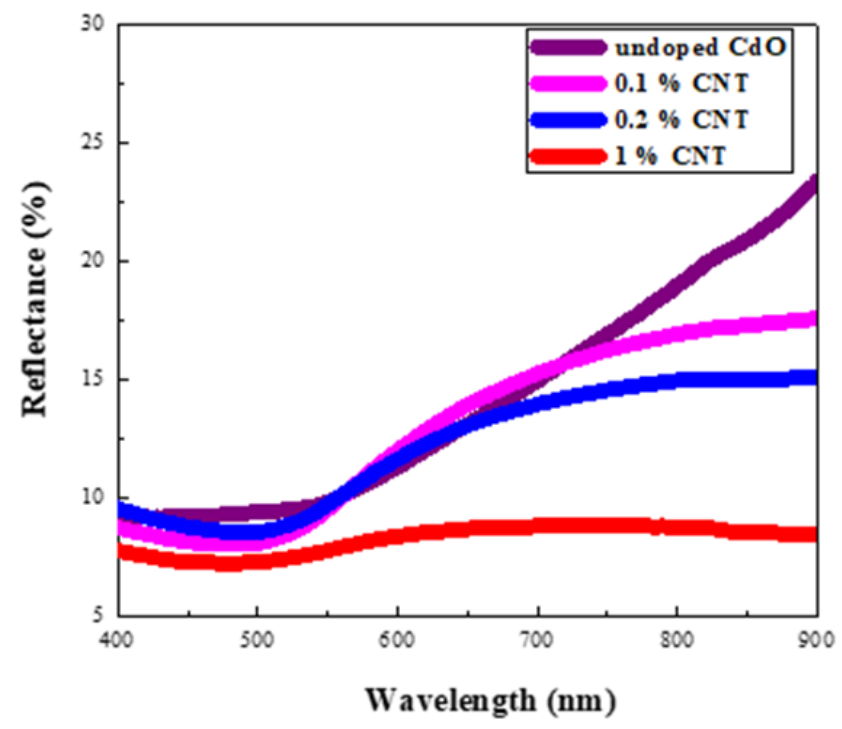

Figure 6. Reflection-wavelength spectrum of $S_{x}$ series samples. 
In Fig. 6, reflectance values were measured (\%) for all samples between 400-900 nm wavelengths. Reflectance values of CNT-doped samples decreased in the reflection-wavelength spectrum graph shown in Figure 6. An increase in reflectance values is observed after $500 \mathrm{~nm}$ wavelength range when the $S_{x}$ series exhibits similar reflectance characteristics at a wavelength range of 400-500 nm. However, a lesser increase is observed in the sample of $1 \%$ CNT added compared to the others. It might be that the reason for this is due to the increase in the rate of CNT in the structure and the difficulty in homogeneous distribution. The $S_{1}$ has the highest reflectance value and the $S_{4}$ has the lowest reflectance value.

In Fig. 7, a graph of the change of the $S_{x}$ series $(a h v)^{2}$ according to hv (photon energy) is given.

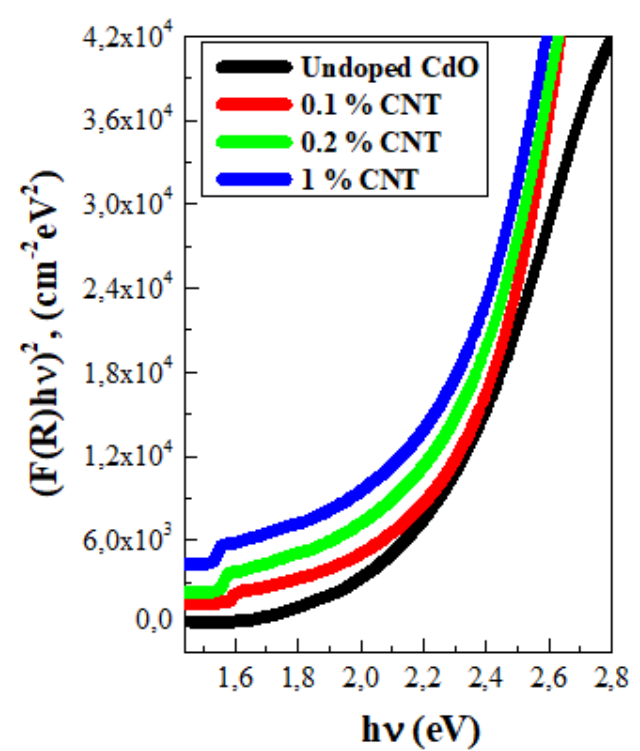

Figure 7. A Graph of The Change of The $S_{x}$ Series $(\alpha h v)^{2}$ According to hv (Photon Energy).

To determine the bandgap values of CNT doped and undoped $\mathrm{CdO}$ nanowires, optical absorption method was used on diffuse reflectance. The Kubelka-Munk function transforms the reflectance values into absorbance. The Kubelka-Munk theory is usually used to analyze the diffuse reflectance spectra obtained from samples with low absorbance. The Kubelka-Munk formula can be expressed by the following relation:

$\mathrm{F}(\mathrm{R})=(1-\mathrm{R})^{2} / 2 \mathrm{R}$

Where $\mathrm{R}$ represents the diffuse reflectance. $\mathrm{F}(\mathrm{R})$ is the Kubelka-Munk function corresponding to the absorbance. F (R) values were converted to linear absorption coefficient with the following relation.

$\alpha=\mathrm{F}(\mathrm{R}) / \mathrm{t}=$ Absorbance $/ \mathrm{t}$

Here $\mathrm{t}$ is the thickness of the sample. It is estimated that $\mathrm{CdO}$ has a direct optical band gap (bandgap). Thus, the optical band gaps of the $\mathrm{CdO}$ samples can be determined using the following relationship.

$$
\begin{aligned}
& \alpha h v=C\left(h v-E_{g}\right)^{1 / 2} \\
& \mathrm{D}=0.9 \lambda / \beta_{h k l} \cos \theta
\end{aligned}
$$

$\mathrm{C}$ is a constant, $\alpha$ absorbance coefficient, and $\mathrm{h} v$ is the photon energy. $\mathrm{h} v$ (photon energy) versus $(\alpha h v)^{2}$ graph, optical absorption method and equation 5. Equation 3 is used when the crystal size of the samples is determined using the Debye-Scherrer relationship. Where D is the crystal size, $\beta_{h k l}$ is the 
peak width of half maximum density, $\theta$ is the diffraction angle and $\lambda$ is the wavelength of the $\mathrm{X}$-ray [30, 31]. The bandgap values calculated in this way are given in Table 2 .

Table 2. Sample contents and $E_{g}$ values.

\begin{tabular}{cccc}
\hline Sample Code & The type of CdO & Amount of CNT (\% w) & Eg (eV) \\
$\mathrm{H}_{1}$ & Commercial & - & 1,75 \\
$\mathrm{~S}_{1}$ & Sol - Gel & - & 1,88 \\
$\mathrm{~S}_{2}$ & Sol - Gel & 0,1 & 2,02 \\
$\mathrm{~S}_{3}$ & Sol - Gel & 0,2 & 1,93 \\
$\mathrm{~S}_{4}$ & Sol - Gel & 1 & 1,84 \\
\hline
\end{tabular}

The bandgap values calculated in Table 2 don't show a decrease or increase parallel to the contribution of CNT. CdO produced by the sol-gel method seems to have a wider $\mathrm{E}_{\mathrm{g}}$ value when compared to $\mathrm{CdO}$ produced by the ready-made $\mathrm{CdO}$ and the left-handed $\mathrm{CdO}$.

\subsection{Comparison of Electrical and Optical Properties of Commercial and Sol-Gel Produced CdO Matrix Composites}

Comparative graphs were drawn to investigate how the properties of the CdO-matrix composite synthesized by the sol-gel method are changed from electrical and optical point of view compared to commercially available $\mathrm{CdO}$. In Figure 8, comparative electrical conductivity plots of samples $S_{1}$ and $H_{1}$ are given.

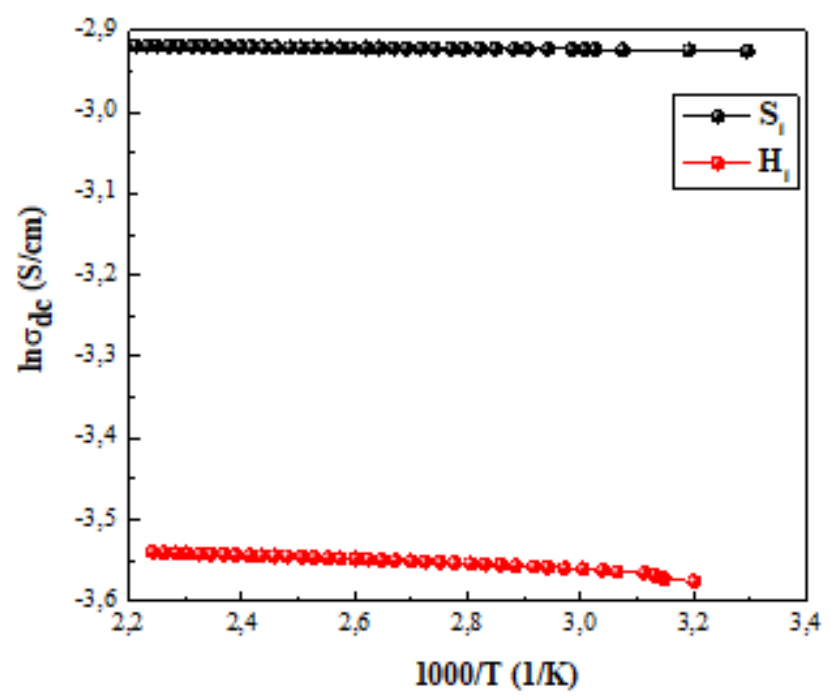

Figure 8. Electrical Properties of the Composites Of Samples $S_{1}-H_{1}$.

The graph of Figure 8 clearly shows that the $\mathrm{CdO}\left(S_{1}\right)$ synthesized by the sol-gel method has better electrical properties than the ready-supplied $\mathrm{CdO}\left(H_{1}\right)$. Figure 9 shows the reflection-wavelength spectrum graph of samples $S_{1}$ and $H_{2}$. 


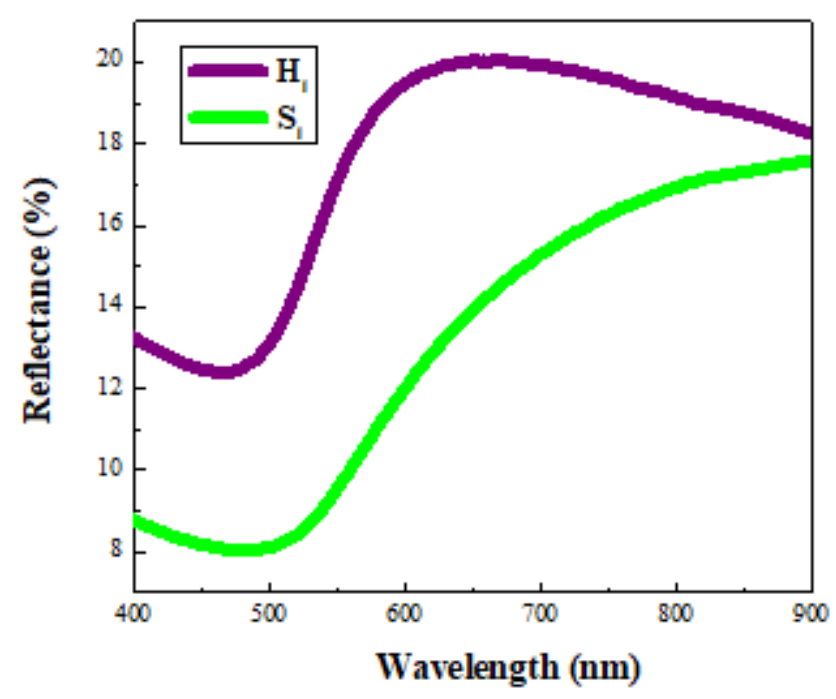

Figure 9. Reflection-Wavelength Spectrum of $S_{1}-H_{1}$ Samples.

The $H_{1}$ sample provided at 400-500 $\mathrm{nm}$ wavelengths has a higher reflectance value than the $S_{1}$ sample synthesized by the sol-gel method. A sharp increase in the reflectance value is observed after $500 \mathrm{~nm}$ for sample $S_{1}$. The CdO synthesized by the sol-gel method exhibits low reflectance at low wave lengths and almost the same reflectance value at $900 \mathrm{~nm}$ wavelength as supplied.

Figure 10 shows a graph of the change of $H_{1}$ (photon energy) of samples $\left(S_{1} H_{1}\right)$ of samples $S_{1}$ $H_{1}$.

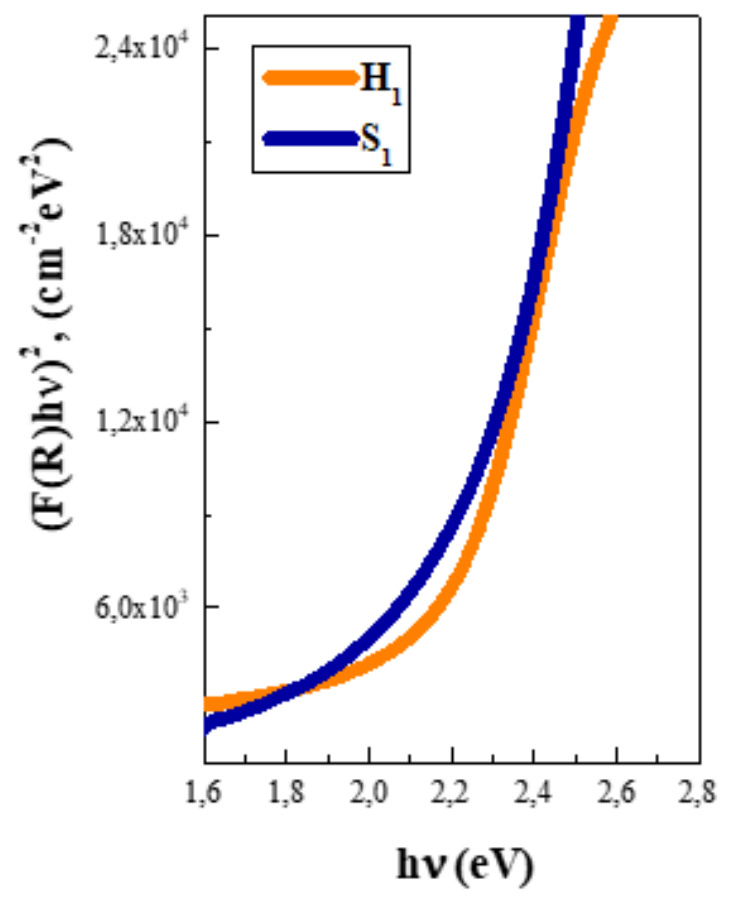

Figure 10. $S_{1} \sim H_{1}$ samples $(\alpha h v)^{2} \sim h v$ (photon energy) change graph.

The $E_{g}$ value of the $H_{1}$ sample was $1.75 \mathrm{eV}$ while the $E_{g}$ value of the $S_{1}$ sample was $1.88 \mathrm{eV}$. It has been found that $\mathrm{CdO}$ synthesized by the sol-gel method broadens the bandgap value. 


\section{Conclusions}

Using the CVD method, carbon nanotubes with diameters ranging from 15 to $25 \mathrm{~nm}$ and varying from 2 to $5 \mu \mathrm{m}$ in diameter were synthesized. The resulting carbon nanotubes were reinforced in commercially available $\mathrm{CdO}$ at $0.1,0.2$ and $1 \%$ to produce composite samples called $\mathrm{H}$ groups. The carbon nanotubes produced by the sol-gel method were reinforced with $0.1,0.2$ and $1 \%$ carbon nodules to produce composite samples called $\mathrm{S}$ groups.

SEM studies of the produced composites showed that the production of a homogeneous composite structure was difficult with the increase of the amount of carbon nanotubes. In samples containing $1 \%$ CNT, it was found that some regions contained carbon nanotubes in bulk without disintegration.

As a result of the electrical examinations of the produced composites depending on the temperature; it was found that the electrical conductivity increased with the carbon nanotube increase in both sample groups. In addition, it has been observed that the CdO-containing composites produced with Sol-Gel have higher electrical conductivities than the CdO-containing composites already provided.

As a result of optical examinations, the forbidden energy ranges of all samples have been determined. In the $\mathrm{H}$ group samples, the forbidden energy range of the pure $\mathrm{CdO}$ sample was found to be $1.75 \mathrm{eV}$ and increased to the maximum level with $0.1 \%$ CNT content with the increase of KNT and then decreased with the increase of CNT. Composite containing $1 \% \mathrm{CNT}$ was found to have a forbidden energy range of pure $\mathrm{CdO}$. For the $\mathrm{S}$ group samples, the forbidden energy range of the pure $\mathrm{CdO}$ sample was found to be $1.88 \mathrm{eV}$ and it was found that it increased to the maximum level with the content of $0.1 \%$ CNT with the increase of CNT and then decreased with the increase of CNT. Composite containing $1 \% \mathrm{CNT}$ was found to have a forbidden energy range of pure $\mathrm{CdO}$.

Consequently, it was determined that the composites using $\mathrm{CdO}$ produced by Sol-Gel showed better performance in terms of electrical and optical properties than the $\mathrm{H}$ group samples.

\section{Acknowledgment}

This study was presented at International Engineering Science and Education Conferences (2018).

\section{References}

[1] Dong, Wenting; Zhu, Congshan. Optical properties of surface-modified CdO nanoparticles, Optical Materials, 22, (2003), 3, pp. 227-233.

[2] LI, Feng; ZHANG, Changwen; ZHAO, Mingwen. Magnetic and optical properties of Cu-doped $\mathrm{ZnO}$ nanosheet: First-principles calculations. Physica E: Low-dimensional Systems and Nanostructures, (2013), 53, pp. 101-105.

[3] GULINO, Antonino; COMPAGNINI, Giuseppe; SCALISI, Alessandro A. Large third-order nonlinear optical properties of cadmium oxide thin films, Chemistry of materials, 15, (2003), 17, pp. 3332-3336.

[4] Farmanzadeh, D., Valipour, A., Adsorption of benzene and toluene molecules on surface of pure and doped cadmium oxide nanosheets: A computational investigation, Applied Surface Science, 450, (2018), pp. 509-515. 
[5] Nawar A. M., Aal N. A., Said N., El-Tantawy, F., \& Yakuphanoglu F., Improving the optical and electrical properties of Zinc Oxide thin film by Cupric Oxide dopant, IOSR J. Appl. Phys, 6, (2014), $4,17-22$.

[6] Azizar M., M.K.R. Rahman Khan, Effect of Annealing Temperature on Structural, Electrical and Optical Properties of Spray Pyrolytic Nanocrystalline CdO Thin Films, Mater. Sci. Semicond. Process, 24, (2014), pp. 26-33.

[7] Yakuphanoglu F., Synthesis and Electro-Optic Properties of Nanosized-Boron Doped Cadmium Oxide Thin Films for Solar Cell Applications, Sol. Energy, 85, (2011), pp. 2704-2709.

[8] Balmuri, S. R., Selvaraj, U., Kumar, V. V., Anthony, S. P., Tsatsakis, A. M., Golokhvast, K. S., \& Raman, T., Effect of Surfactant in Mitigating Cadmium Oxide Nanoparticle Toxicity: Implications for Mitigating Cadmium Toxicity İn Environment, Environmental research, 152, (2017), pp. 141149.

[9] Zheng, B.J., Lian, J.S., Zhao, L., Jiang, Q., Optical and Electrical Properties of In- Doped CdO Thin Films Fabricated by Pulse Laser Deposition, Applied Surface Science, 256, (2010), 9, pp. 29102914.

[10] Coutts, T.J., Young, D.L., Li, X., Mulligan, W.P., Wu, X., Vac, J., 2000. "Search for Improved Transparent Conducting Oxides: A fundamental investigation of $\mathrm{CdO}, \mathrm{Cd}_{2} \mathrm{SnO}_{4}$, and $\mathrm{Zn}_{2} \mathrm{SnO}_{4}$, Journal of Vacuum Science \& Technology A: Vacuum, Surfaces, and Films, 18, (2000), 6, pp. 26462660.

[11] Metz A.W., Ireland J.R., Zheng J.G., Lobo R.P., Yang Y., Ni J., Stern C.L., Dravid V.P., Bontemps N., Kannewurf C.R., Poeppelmeier K.R., Marks T.J., Transparent conducting oxides: texture and microstructure effects on charge carrier mobility in MOCVD-derived CdO thin films grown with a thermally stable, low-melting precursor, Journal of the American Chemical Society, 126, (2004), 27, pp. 8477-8492.

[12] Kumaravel, R., et al., Electrical, optical and structural properties of aluminum doped cadmium oxide thin films prepared by spray pyrolysis technique, Materials Chemistry and Physics, 122, (2010), 2-3, pp. 444-448.

[13] Bhosale, C.H., Kambale, A.V., Kokate, A.V., Rajpure, K.Y., Structural, optical and electrical properties of chemically sprayed CdO thin films, Materials Science and Engineering B, 122, (2005), pp. 67-71.

[14] Uplane, M. D., et al., Stability and electronic properties of ZnxCd1-xO alloys, Mater. Chem. Phys, 1, (1999), pp. 8630.

[15] Peter, L.M., The photoelectrochemical properties of anodic Bi2S3 films, Journal of Electroanalytical Chemistry and Interfacial Electrochemistry, 98, (1979), 1, pp. 49-58.

[16] Yufanyi, Divine Mbom, et al., CdO nanoparticles by thermal decomposition of a cadmiumhexamethylenetetramine complex, Journal of Materials Science Research, 3, (2014), 3, pp. 1.

[17] Ye, M., Zhong, H., Zheng, W., Li, R., \& Li, Y., Ultralong cadmium hydroxide nanowires: synthesis, characterization, and transformation into CdO nanostrands, Langmuir, 23, (2007), 17, pp. 9064-9068. 
[18] Zhang, J., Wang, Y., Lin, Z., Huang, F., Formation and Self-Assembly of Cadmium Hydroxide Nanoplates in Molten Composite-Hydroxide Solution, Crystal Growth \& Design, 10, (2010), 10, pp. 4285-4291.

[19] Prakash, T., Arunkumar, T., Sathıysa Raj, D., Jayaprakash, R., Surfactant-liaised Variation in CdO Nanocomposites Morphology, Physics Procedia, 49, (2013), pp. 36-43.

[20] Ghoshal, T., Biswas, S., Nambissan, P. M. G., Majumdar, G., De, S. K., Cadmium Oxide Octahedrons and Nanowires on the Micro-Octahedrons: A Simple Solvothermal Synthesis, Crystal Growth \& Design, 9, (2009), 3, pp. 1287-1292.

[21] Tadjarodi, A., Imani, M., A novel nanostructure of cadmium oxide synthesized by mechanochemical method, Materials Research Bulletin, 46, (2011), 11, pp. 1949-1954.

[22] Tadjarodi, A., Imani, M., Synthesis and characterization of CdO nanocrystalline structure by mechanochemical method, Materials Letters, 65, (2011), 6, pp. 1025-1027.

[23] Shi, W., Wang, C., Wang, H., Zhang, H., Hexagonal Nanodisks of Cadmium Hydroxide and Oxide with Nanoporous Structure, Crystal Growth \& Design, 6, (2006), 4, pp. 915-918.

[24] Andeani, J. K., Mohsenzadeh, S., Phytosynthesis of Cadmium Oxide Nanoparticles from Achillea wilhelmsii Flowers, Journal of Chemistry, 2013, (2012), pp. 1-4.

[25] Ramazani, M., Morsali, A., Sonochemical syntheses of a new nano-plate cadmium (II) coordination polymer as a precursor for the synthesis of cadmium (II) oxide nanoparticles, Ultrasonics Sonochemistry, 18, (2011), 5, pp. 1160-1164

[26] Aydın, C., El-Nasser, H. M., Yakuphanoglu, F., Yahia, I. S., \& Aksoy, M., Nanopowder synthesis of aluminum doped cadmium oxide via sol-gel calcination processing, Journal of Alloys and Compounds, 509, (2011), 3, pp. 854-858.

[27] Duclaux, L., Review of the doping of carbon nanotubes (multiwalled and singlewalled), Carbon, 40, (2002), 10, pp. 1751-1764.

[28] Kumar, S. S., Vairam, S., Neelakandeswari, N., \& Aruna, S., Effect of metal oxide charge transfer layers on the photovoltaic performance of carbon nanotube heterojunction solar cells, Materials Letters, 220, (2018), pp. 249-252.

[29] S.P. Yakala, S.S. Yawale, G.T. Lamdhade, Tin oxide and zinc oxide based doped humidity sensors, Sensors and Actuators A: Physical, 135, (2007), pp. 388-393.

[30] Ates, T.; Tatar, C., Yakuphanoglu, F., Preparation of semiconductor ZnO powders by sol-gel method: Humidity sensors, Sensors and Actuators A: Physical, 190, (2013), pp. 153-160.

[31] S.P. Yawale, S.S. Yawale, G.T. Lamdhade, Tin oxide and zinc oxide based doped humidity sensors, Sensors and Actuators A: Physical, 135, (2007), pp. 388-393. 